\title{
Understanding Spatial and Temporal Processes of Urban Growth:
}

\section{Cellular Automata Modelling}

\author{
Jianquan Cheng $\dagger^{*}, \quad$ Ian Masser $\dagger$
}

\author{
$\uparrow$ Department of Urban and Regional Planning and Geo-information Management, International \\ Institute for Geo-Information Science and Earth Observation (ITC), Hengelosestraat 99, P.O.Box \\ 6, 7500 AA Enschede, The Netherlands; e-mail: jianquan@itc.nl, masser@itc.nl \\ School of Urban Studies, Wuhan University, P.R.China
}

\begin{abstract}
Understanding the dynamic process of urban growth is a prerequisite to the prediction of land cover change and the support of urban development planning and sustainable growth management. The spatial and temporal complexity inherent in urban growth requires the occurrence of a new simulation approach, which should be process-oriented and have a stronger capacity of interpretation. This paper presents an innovative methodology to understand spatial processes and their temporal dynamics on two interrelated scales (municipality and project), by a multi-stage framework and dynamic weighting concept. The multi-stage framework aims to model local spatial processes and global temporal dynamics by incorporating explicit decisionmaking processes. It is divided into four stages: project planning, site selection, local growth and temporal control. These four steps represent the interactions between top-down and bottom-up decision making involved in land development of large-scale projects. Project-based cellular automata modelling is developed for interpreting the spatial and temporal logic between various projects forming the whole urban growth. Dynamic weighting attempts to model local temporal dynamics at the project level as an extension of the local growth stage. As a non-linear function of temporal land development, dynamic weighting is able to link spatial processes and temporal patterns. The methodology is tested with reference to the urban growth of a fast growing city,
\end{abstract}


Wuhan in the Peoples' Republic of China from 1993 to 2000. The findings from this research suggest that this methodology can facilitate the interpretation and visualisation of the dynamic process of urban growth more temporally and transparently, globally and locally.

Keywords: urban growth, spatial and temporal processes, cellular automata, multi-stage, dynamic weighting.

\section{Introduction}

Understanding of urban development process is highly crucial in urban development planning and sustainable growth management. The urban development process involves multi-actors, multibehaviours and various policies, which results in its spatial and temporal complexity. The nonlinear dynamics inherent in these growth processes opens up the possibility for emergencies (sudden changes) that are difficult or impossible to predict. Due to the hidden complexity of reality, our science has become less orientated to prediction but more as an aid to understanding, to structure debate (Batty and Torrens, 2001). Orjan (1999) argued that without a proper understanding of the recent past we are in no position to comprehend- let alone predict-emerging patterns and processes. Couclelis (1997) first put forward the idea of a spatial understanding support system (SUSS). Horita (2000) reported a new SUSS for representing community disputes. Limited by existing sciences and techniques, understanding-oriented modelling is more practicability than prediction-oriented, or rather, a proper understanding of complex system is the prerequisite to its prediction. Towards reasonable understanding, we need reliable information sources and models. Successful models should have a stronger capacity for interpretation and interactive environment to simulate 'what-if' scenarios. Consequently, it requires an innovative simulation approach. The first step to aid such decision-making is to identify the process of decision-making. This is the same as the area of information management, where we need to recognise the data flow chart and data model before establishing any operational information system. 
Remote sensing and geographical information science (GIS) have been proven an effective means for extracting and processing varied resolutions of spatial information for monitoring urban growth (Masser, 2001). However, they are still not adequate for process-oriented modelling as they lack social and economic attributes in particular on detailed scales. In developing countries, socio-economic data acquisition and integration still have a long way to go. On this occasion, local knowledge (expert opinions, historical documents), albeit only qualitative or semiquantitative, can be very valuable in assisting process understanding such as urban growth patterns, driving forces and major actors involved. Hence, local knowledge should be incorporated into simulation modelling at certain stage and in certain ways.

Cellular automata (CA), a technique developed recently, has been receiving more and more attention in urban and GIS modelling due to its simplicity, transparency, strong capacities for dynamic spatial simulation, and innovative bottom-up approach. When applied to real urban systems, CA models have to be modified such as multi-states of cell, relaxing size of neighbourhood with distance-decay effects, probabilistic rules, and link with complexity theory. In fact, many-if not all-urban CA bear little resemblance to the formal CA model (Torrens and O'Sullivan, 2001). Numerous literature can be seen in the field of urban CA modelling, which include at least two classes of successful applications on various spatial and temporal scales. One is concentrated on artificial cities to test the theories of complexity and urban studies (Couclelis, 1997; Benati, 1997; Batty, 1998; Wu, 1998). Another is focused on real cities to aid decision support of urban planning at the regional, municipal and town levels (Besussi et al., 1998; Clarke and Gaydos, 1998; Ward et al., 2000; White and Engelen, 2000; Yeh and Li, 2001; Silva and Clarke, 2002; Wu, 2002). These studies have revealed that urban CA-like models are effective in simulating the complexity of urban systems and its sub systems from emergence, feedback and self-organisation. Nevertheless, the interpretation of transition rules, which is highly important for urban planners, still receives little attention in urban CA modelling, particularly in linking with the process of urban planning. 
Moreover, previous studies of urban CA models ignore the fact that urban growth is a dynamic process rather than a static pattern. For example, the urban growth model of Clarke and Gaydos ( 1998) has attracted a lot of attention in urban growth prediction e.g.(Silva and Clarke, 2002). Their CA model controls the evolution of city growth by five coefficients (diffusion, breed, spread, slope and roads). The diffusion factor determines the overall outward dispersive nature of the distribution. The breed coefficient specifies how likely a newly generated detached settlement is to begin its own growth cycle. The spread coefficient controls how much diffusion expansion occurs from existing settlements. The slope resistance factor influences the likelihood of settlement extending up steeper slopes. The road-gravity factor attracts new settlements toward and along roads. This is a successful simulation model of patterns, which principally focuses on such patterns as spontaneous, organic, spread, road-influenced and diffusive. It still lacks the capacity of interpretation of casual factors to be a complete process model because similar patterns from the final outputs of CA simulation do not indicate similar processes. Thus, the transition rules validated are not evidential to explain the complex spatial behaviours behind the process. Therefore, process rather than pattern-oriented simulation should be the main concern of new urban growth CA modelling. This point is supported and recognised recently in some journals (Torrens and O'Sullivan, 2001). Dragicevic et al.(2001) apply fuzzy spatio-temporal interpolation to simulate changes that occurred between snapshots registered in a GIS database. The main advantage of the research lies in its flexibility to create various temporal scenarios of urbanisation processes and to choose the desired temporal resolution. The authors also declared that the approach does not explicitly provide causal factors, thus it is not an explanatory model.

Wu (1998) developed an AHP-driven CA model to simulate the spatial decision-making process of land conversion. AHP refers to analytical hierarchy process originated by Saaty (1980). The AHP uses pair-wise comparisons to reveal the preferences of decision makers. AHP is an ideal means for calculating weight values from the qualitative knowledge of local experts. This CA 
model is in essence a dynamic Multi-Criteria Evaluation (MCE) as a dynamic neighbourhood (updated during model iteration) is treated as an independent variable. This model is successful in linking explicit decision-making processes with CA. The adjustment of factor weights is able to generate distinguishing scenarios. Hence, this model has a stronger capacity of interpretation. However, the AHP-driven decision-making process is not spatially and temporally explicit as the weight values are fixed for the whole study area and for the whole period of modelling. They are not able to model process especially temporal dynamics. The incorporation of spatially and temporally explicit decision-making processes into CA model has not been reported so far.

In summary, we need to develop a new methodology based on present urban CA, which is able to model and interpret spatial process and temporal dynamics, and also incorporates local knowledge for interpreting these processes. With this in mind, this paper is organised into four sections. Following the introduction, the next section first introduces the concepts regarding urban growth understanding: process, dynamics, global and local; second discusses in detail a proposed methodology, which mainly comprises a multi-stage framework and dynamic weighting concept. The former incorporates explicit decision-making processes into modelling of local spatial processes and global temporal dynamics. The latter continues to model local temporal dynamics by representing the dynamic interaction between pattern and process at a lower level. CA-based simulation is developed to support and implement each method. Their mathematical models are described step by step. Section three focuses on the implementation of the methodology by a case study of Wuhan City, P.R.China. Section four ends with some further discussion and conclusions. 


\section{Methodology}

\subsection{Complex processes and dynamics}

Urban growth can be defined as a system resulting from the complex interactions between urban social and economic activities, physical ecological units in regional areas and future urban development plans. This interaction is an open, non-linear, dynamic and local process, which leads to the emergence of global growth patterns. The urban growth process is a self-organised system(Allen, 1997).

Process generally refers to the sequence of changes in space and time; the former is called spatial process, the latter temporal process. It should be noted that strictly speaking spatial and temporal process can not be separated exactly as any geographical phenomena are bound to have a spatial and temporal dimension. Understanding change through both time and space should, theoretically, lead to an improved understanding of change and of the processes driving change (Gregory, 2002). However, the spatial process is much more than any sequence of changes. It implies a logical sequence of changes being carried on in some definite manner, which lead to a recognisable result (Getis and Boots, 1978).

Summing up, the key components of process are change and logical sequence. The former is defined by a series of patterns and the latter implies an understanding of process. In contrast to pattern, process contains a dynamic component.

An urban growth system consists of a large number of new projects on varied scales. Large-scale projects are characterised by dominant functions, heavy investment, long term construction and a number of actors involved; examples include airports, industrial parks, and universities. In contrast, small-scale projects are characterised by single function, rapid construction, light investment, and few actors; examples can be a private house and a small shop. The project, as the basic unit of urban development, is the physical carrier of complex social and economic activities. 
The spatial and temporal heterogeneity of social and economic activities create massive flows of matter, people, energy and information between new projects and also between the projects and the other systems (developable, developed and planned). They are the sources of the complex interactions inherent in urban growth. As such, the urban growth process is the spatial and temporal logic between varied scales of land development projects. The spatial and temporal organisation of projects is the key to understanding processes and dynamics. This understanding can be based on two scales: municipality (global) and project (local). For instance, on global scale, in space, projects can be organised into clustered or dispersed patterns, the former implies a self-organised process, the latter a stochastic process. In time, projects can be organised into quick or slow patterns. The local process refers to spatial growth at the project level. Global dynamics means the temporal logic between the projects forming the whole urban growth, local dynamics only the temporal logic between the spatial factors or elements within a project. This

research has two specific objectives towards systematically understanding the spatial and temporal process of urban growth:

- To understand the local spatial process at the project level and the global temporal dynamics based on a multi-stage framework;

- To understand local temporal dynamics at the project level based on dynamic weighting concept.

\subsection{A conceptual model for global dynamics}

The complexity of the urban growth process can intuitively be projected onto decision-making processes, and the spatial/temporal dimensions. The former involves multiple actors and behaviours. The latter involves various spatial and temporal heterogeneity. Or we can say, the former is a cause, the latter the effect and projection. In consequence, we must start with the decision making process to understand the spatial and temporal processes of urban growth. 
Decision making in urban growth is related to plans, policies and projects. Projects are special land use or development proposals initiated usually by various levels of actors such as investors, planners, developers, land owners and work units. They evolve in the context of various levels of policy and plans. The project development process is a dynamic nested hierarchy of multiple decision-making procedures spatially from municipal to building level and vice versa. The global dynamics of urban growth results from the interactions between the top-down and bottom-up processes of decision-making. Top-down decision-making includes financial resources allocation, master planning, and time schedule of projects; with bottom-up decision-making containing building style, building density, and plot ratio.

Global patterns can be described as a cumulative and aggregate order that results from numerous locally made decisions involving a large number of intelligent and adaptive agents. On the municipal scale, its decision making process can fall into four stages: project planning, site selection, local growth and temporal control, as illustrated in figure 1.
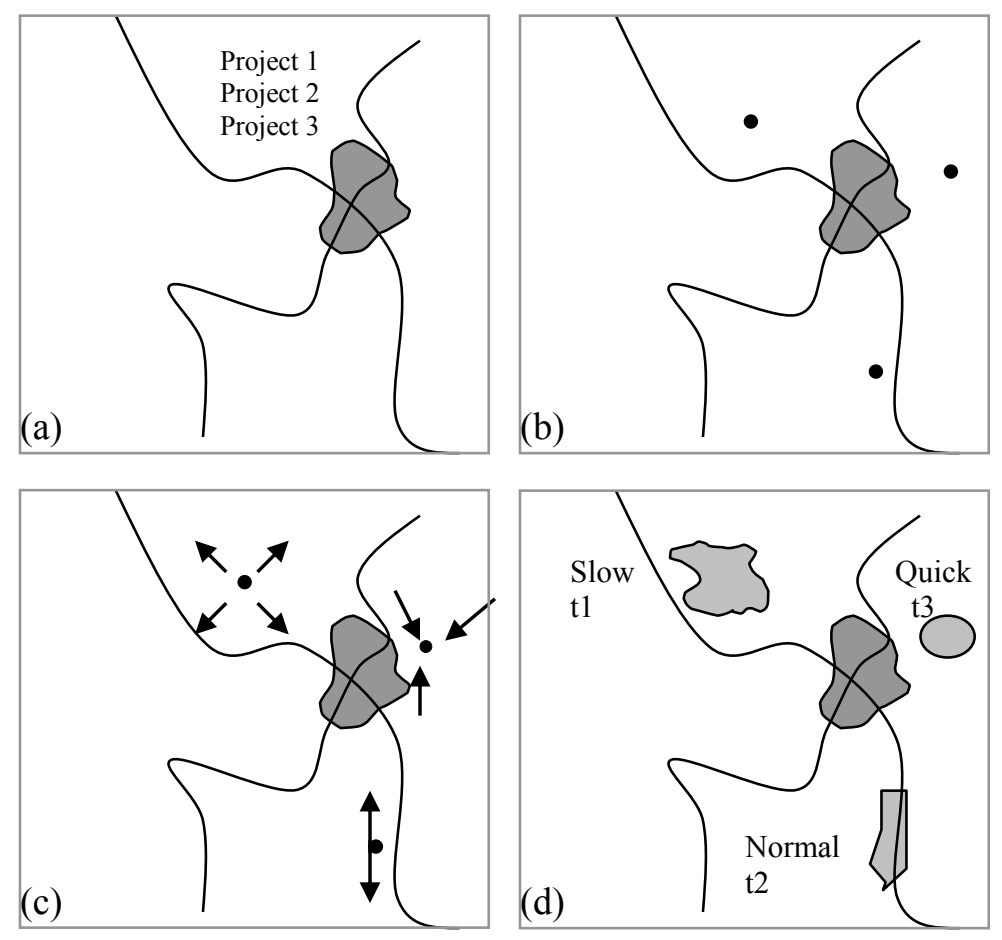

Figure 1. A conceptual model of the decision-making process (a): project planning; (b): site selection; (c): local growth and (d): temporal control 
The first stage (project planning) answers the questions "how many large-scale projects were planned in the past periods?" and "how much area was constructed in each project ?" This stage is a typical top-down decision-making process based on the systematic consideration of physical and socio-economic systems. Municipalities need to plan land consumption according to their social-economic development demand. When land consumption is projected onto the physical land cover system, it results in different scales of new projects. Land development projects can be divided into spontaneous and self-organisational types ( $\mathrm{Wu}, 2000)$. The former corresponds to small scale or sparse development, which may contain more stochastic disturbance and involve lower level actors such as individuals or organisations. The latter represents larger-scale projects with a dominant land use and higher level of actors. They are the main concern of this project planning stage. The project here can be called an 'agent', which is a spatial entity linking with distinct actors and spatial and temporal behaviours. In this sense, the project-based approach proposed here is also a kind of agent-like modelling.

The first stage belongs to non-spatial modelling, resulting in proposals for development projects. These new developments will be projected in their spatial and temporal dimensions. Spatial complexity can be considered from two aspects: location of site and spatial interactions among sites. The former is the issue of spatial site selection or location, which is becoming the second stage. The latter is the issue of local growth or the control of development density and pattern, the third stage of the framework. Temporal complexity, which is typically indicated by temporal heterogeneity or the timing of local growth, will be described in the temporal control section.

The second stage (site selection) deals with the question "where were the various scales of projects located?" This stage is a typical spatial decision process involving municipal decisionmakers. This aims to systematically optimise and balance the spatial distributions of socioeconomic activities as each project has specific socio-economic functions planned. This stage is the static projection of the projects planned at the first stage. The rules of site selection are represented by multiple physical, socio-economic and institutional factors, incorporating various 
global and local constraints. Rules are differentiated between planned projects in terms of influential factors, weights and constraints. To some extent, the stage provides growth boundaries and seeds for the next stage (local growth). Apparently, this site selection stage results in a number of potential spatial sub-systems through the top-down process.

The third stage (local growth) copes with the question "how did each project grow locally?" This question includes development density, intensity and the spatial organisation of development units. After being spatially located, each project was developed based on more local decisionmaking from land owners, investors and individuals. This results in different spatial processes. The outcomes of these local growth processes can be concentric, spread, road-influenced and leap-frog. They are affected by numerous factors, which change their influential roles spatially and temporally. The spatial heterogeneity (heterogeneity in a spatial context means that the parameters describing the data vary from place to place) suggests that spatial processes are locally varied. In spatial statistics, global analysis is being complemented by local area analysis such as Local Indicators of Spatial Association (LISA) (Anselin, 1995) and Geographically Weighted Regression (GWR) (Fotheringham and Rogerson, 1994). As for understanding local urban growth, its spatial process mostly depends on the local conditions, which include not only physical constraints but also the socio-economic circumstance. Based on cellular automata, we are able to explore the dominant causal factors locally. The stage is dominated by the bottom-up approach.

The last stage (temporal control) answers the question "How fast did each project grow temporally?" This stage shifts to master the local growth speed from a global perspective. The image of the whole urban growth process comprises temporal sequences of all projects. For example, we can define such patterns as quick, basic or normal and slow local growth representing three identifiable timing modes. The rate of local growth is governed by numerous factors resulting from top-down and bottom-up decision making. For example, the former includes financial resources allocation from higher-level organisations and master and land use 
planning control. The latter include man-power allocation and facility supply. The temporal land demand amount decided at this stage should be input as a guide or constraint to the local growth stage. Hence, the stage is primarily a top-town procedure for controlling local temporal patterns and conditioned by a bottom-up one.

It should be noted that each stage described above involves the interactions between top-down and bottom-up decision-making. For example, although the land demand of each project is planned by municipal organisations, actual consumption is influenced by a number of local constraints. The whole process of urban growth should contain numerous feedback loops between both on various spatial and temporal scales. To be a focus, top-down socio-economic modelling at certain stages are treated as exogenous variables in this research.

This framework is primarily designed for understanding the dynamic processes of urban growth. When used for planning support, the first question will become "How many large-scale projects will be planned in the coming years". The socio-economic model for determining land consumption should be included at this stage in this case. The other questions at various stages will follow similar modification. Such a multi-stage framework can offer a transparent and friendly environment for constructing various scenarios of plans.

\subsection{Land transition model}

The multi-stage framework discussed above has conceptually transformed the global dynamics of the whole urban growth process into the local land conversion processes of large-scale projects. These local processes have complex spatial and temporal interactions between them, which can be simulated by urban CA approach. The identification of large-scale projects and their functions is of importance for understanding the spatial behaviour of relevant actors. 'Large-scale' has two meanings from the spatial and socio-economic perspective respectively. One refers to a certain scale of spatial clustering of new development units. The project defined in this way may have no definite socio-economic implication as it was not planned as a complete spatial entity. This is a 
relative spatial division. Another refers to larger-area land development with special socioeconomic functions such as car manufacturing centre. The project defined in this way may have no ideal spatial agglomeration as it is low in building density. To be a focus on interpretation, the latter is highlighted in this research as it is linked to the underlying socio-economic activities. However, it should be noted that the former is also significant and necessary in some spatial process modelling. Small-scale projects with mixed functions are conceptually merged into one class. Historical documents and interviews with local planning organisation are a necessary means for identifying large-scale projects. As the process of CA modelling is identical to each project, as an example, we only refer to project $d$ in the following description; the other projects follow the same procedures.

\subsubsection{Project planning}

$$
\left.L(t)\right|_{t=n}=L_{d}
$$

Here, $L_{d}$ is the actual (or planned) area of land development project $d$ (from stage 1) in the whole period $[t=1 \sim n] . L_{d}$ in principle should result from traditional top-down socio-economic models e.g. (White and Engelen, 2000). Here it is assumed to be an exogenous variable (known value from the urban growth analysis of past years), for example, a shopping centre occupied 5 ha from 1993 to 2000 , i.e. $L_{d}=5$ (ha). $L(t)$ is the simulated area of land development project $d$ till time $t$, $L(1996)$ means the simulated land transition amount from 1993 to 1996. $L(t)$ will be calculated from the section of temporal control.

\subsubsection{Constraint-based site selection model}

$$
\text { Sites }=\text { Neighbourhood } * \text { Center }(x, y), \quad \text { Center }(x, y)=\prod_{i=1}^{m} \text { Cons }_{i}
$$


Here, site selection of projects includes a central point and its surrounding spatial extent or neighbourhood. The location of the centre is determined by various critical constraints. Like other research (Ward et al., 2000; Yeh and Li, 2001), constraints operate at the local, regional and global levels. Global constraints taking an account of the whole study area include physical (e.g. ecological protection zone, accessibility to transport infrastructure and city centres/sub-centres), and economic (e.g. investment, land value), social (population density) and institutional (master planning) aspects. Regional constraints are defined by the availability of the developable or developed land and its density in a neighbourhood. It should be noted that the regional level has a varied spatial extent as the size of neighbourhood varies from project to project. In some cases, we have to define multi-level regions e.g.(Batty et al., 1999). Local constraints refer to the physical conditions of a site or pixel such as slope, soil quality, and geological condition. All the criteria at three levels vary from project to project, and from case to case, as they should be able to interpret the specific spatial behaviours of the actors involved in each project. For example, slope does not take effect in a flat city. Equation 2 is based on the assumption that site selection depends on a limited number of equally weighting constraints as in practice decision making process is primarily qualitative and simple among decision makers. This stage is implemented by GIS analysis based on spatial operation (e.g. 'find distance', 'neighbourhood statistics', and 'map calculation') and by heuristic rules operation (e.g. if rule 1 and rule $2 \ldots$ then do) based on visual programming. GIS visual functions can help modellers test their systematic thinking i.e. whether this rule can create ideal sites for a planned project.

\subsubsection{Local growth model}

This model aims to seek major spatial determinants for interpreting local spatial process based on bottom-up CA simulation. Cellular automata are dynamic discrete space and time systems. A cellular automaton system consists of a regular grid of cells, each of which can be in one of a 
finite number of possible states, updated synchronously in discrete time steps according to a local, identical interaction rule. In this model, the cell state is binary (1-land cover transition from nonurban to urban, 0-not), limited in the cellular space of each project. CA simulation is carried out by dynamic evaluation and updating of the development probabilities at each cell in the cellular space. The cells selected in each iteration will be changed from 0 to 1 . The development potential of each cell $j$ at time $t$ is defined as:

$$
P_{j}(t)=\sum_{i=1}^{k} W_{i}(t) * V_{i j}(t) \prod_{i=k+1}^{m} \omega_{i}
$$

Where $P_{j}(t)$ refers to the development potential of cell $j$ at time $t$. It is assumed that totally $m$ constraints $(1 \leq i \leq m)$ are considered, comprising $k$ non-restrictive and $m$ - $k$ restrictive constraints. When $k+1 \leq i \leq m, \omega_{\mathrm{i}}$ is a binary variable ( 0 or 1$)$ representing restrictive constraints from local, regional and global levels (equation 3 ). $\omega_{\mathrm{i}}=0$ means that a cell is absolutely restricted from transition into urban use in relation to constraint $i$, e.g. the centre of a large lake.

When $1 \leq i \leq k$, they are non-restrictive constraints or named factors in order to be distinguished from restrictive constraints. These factors complementarily contribute to the development potential of a cell. The potential of transition depends on a linear weighted additive sum of development factors. $W_{i}(t)$ is the relative weight value of factor $i$ to be calibrated from data. Largely, $W_{i}(t)$ interpret the casual-effects of local growth process. In the case of global temporal dynamics, $W_{i}(t)$ is treated temporally as constant $W_{i}$. The functions $W_{i}(t)$ will be discussed in detail in the next section of local temporal dynamics. $V_{i j}(t)$ is the standardised score (within the range $0 \sim 1$ ) of factor $i$ at cell $j$ at time $t$. In urban growth, the frequently selected factors include transport accessibility, urban centres/sub-centres accessibility, suitability, planning input and dynamic neighbourhood e.g. (White et al., 1997; Clarke and Gaydos, 1998; Wu, 1998; Ward et al., 2000). Suitability analysis has been implemented at the stage of site selection. The other four 
factors are selected for evaluating $P_{j}(t)$ at this stage. For accessibility factors such as the accessibility to a major road, a negative exponential function is employed to quantify the distance-decay effect $V_{i j}(t)$ (equation 4). Urban models based on economic theory (Muth, 1969) and discrete choice theory (Anas, 1982) made widespread use of the negative exponential function. Previous research for the same case study (Cheng and Masser, 2003) confirmed its effectiveness although the inverse power function has also frequently been successfully employed for quantifying the distance-decay effect (Batty and Kim, 1992).

$$
V_{i j}(t)=e^{-\phi d i j} \quad 0 \leq V_{i j}(t) \leq 1, \quad 1 \leq i \leq k
$$

Where $d_{i j}$ is the distance from cell $j$ to any spatial element defined in factor $i$ such as to a major road network. $\phi$ is gradient of density for quantifying its spatial influence degree on land transition. Usually, $0<\phi<1$, and $\phi$ varies with factor $i$. The parameter $\phi$ can be determined by global exploratory data analysis of urban growth pattern (Cheng and Masser, 2003), where $\phi$ is a slope value of the log-linear relationship between probability of transition and distance $d_{i j}$. Equation 4 calculates the potential of land conversion $V_{i j}(t)$ contributed from any proximity factor. In this study, accessibility factors are fixed or static during the modelling period as the spatial factors (e.g. road networks) are not updated temporally, so $V_{i j}(t)=V_{i j}$.

In our model, neighbourhood size is not globally universal but locally parameterised, which varies with different projects. The neighbourhood effect (action-at-distance) is represented as a non-restrictive factor in equation 3, which indicates the spatial influences of developed cells on land conversion in surrounding sites. Developed cells come from the previously transited cells or the old urban area. Strictly speaking, the former reflects the local spatial self-organisation of land conversion in each project as a dynamic variable updating in each iteration. The latter depends on 
existing global urban activities as a fixed spatial factor. They are treated as two independent factors in this research.

In practice, restrictive and non-restrictive constraints are a relative division. They are temporally varied. For example, ponds may be a restrictive constraint in 1950 but become non-restrictive in 2000 as no large quantity of developable land is available in the later period.

$$
\begin{gathered}
P_{j^{\prime}}(t)=\left(1+\ln (\xi)^{a}\right) P_{j}(t) \\
\Delta L(t)=L(t)-L(t-1), \quad L(0)=0
\end{gathered}
$$

Principally, land conversion is allocated according to the highest score of the potential, however, practically, this is subject to stochastic disturbance and imperfect information. To generate the patterns that are closer to reality, a stochastic disturbance is introduced as $\left(1+\ln (\xi)^{\alpha}\right)(\mathrm{Li}$ and Yeh, 2001). $\xi$ is a random variable within the range [0 1]. $\alpha$ is a parameter controlling the size or strength of the stochastic perturbation. Like other CA applications (White et al., 1997; Wu and Webster, 1998; Ward et al., 2000), $P_{j^{\prime}}(t)$ in equation 5 represents the probability of land transition at cell $j$ at time $t$, which is the major driving force of local growth.

Whether a cell is to be transited or not from time $t-1$ to $t$ depends on the probability $P_{j^{\prime}}(t)$ at each iteration. Selection will start from the maximum of $\left\{P_{j^{\prime}}(t)\right\}$ until it reaches the required number of cells, i.e. $\Delta L(t)$ for the iteration between time $t-1$ and $t$. The demand of land consumption $\Delta L(t)$ in equation 6 will be calculated from the stage of temporal control as $L(t)$ is the accumulative amount of land development until time $t$.

\subsubsection{Temporal control model}


Previous studies suggest that urban development process $L(t)$ in equations 1 and 6 follows a logistic curve over time (Herbert and Thomas, 1997). For example, Sui and Hui (2001) simulated the expansion trend of the desakota regions between 1990 and 2010 by using a logistic equation, where the total number of converted urban pixels was a logistic function of the year. Here, the same principle is applied for the temporal control of each project. A standard logistic curve is illustrated in equation 7.

$$
L(t)=\frac{a}{1+b^{*} e^{-c t}}
$$

Where $a, b$ and $c$ are unknown parameter, $t(1 \sim \mathrm{n})$ the time step and $L(t)$ the amount of land development till time $t$. If it is assumed that $L(0)=L_{0}=a /(1+b)=1, L(n)=L_{n}=a /\left(1+b e^{-c n}\right)=L_{d}$, Here, $n, L_{d}$ are the same definition as in equation 1, the equation 7 can be revised as in equations 8 and 9:

$$
\begin{gathered}
L(t)=\frac{x}{1+(x-1) * e^{-c t}} \\
x=\frac{L d\left(e^{-c n}-1\right)}{e^{-c n}-L d}
\end{gathered}
$$

$X$ in equation 8 and 9 implies the long-term limit of $\mathrm{L}(\mathrm{t})$ behaviour. The shape of the logistic curve usually represents the speed of project development over time, which is controlled by the parameters $c, n$ and $L_{d}$. Here, in simplicity, temporal control is classified as three types: slow growth, normal growth and quick growth, which indicates three distinguishing scenarios. If it is assumed that $\mathrm{L}(\mathrm{t})=L_{d} / \lambda$ when $\mathrm{t}=\mathrm{n} / 2, \mathrm{c}=2 \log \left(\left(L_{d}-\lambda\right) /(\lambda-1)\right) / n$. Further, $L(t)$ can be the function of both time $t$ and parameter $\lambda$ when $n$ and $L_{d}$ are set.. Consequently, the value of $\lambda$ will determine the shape of logistic curve. As such, we can define slow, normal and quick growth in 
equation 10 according to $\lambda$. Of course, we can define more classes such as 'very slow', 'very quick' by assigning different $\lambda$ value.

"Quick growth": $\quad \lambda=4 / 3$

"Normal growth": $\lambda=2$

"Slow growth": $\quad \lambda=4$

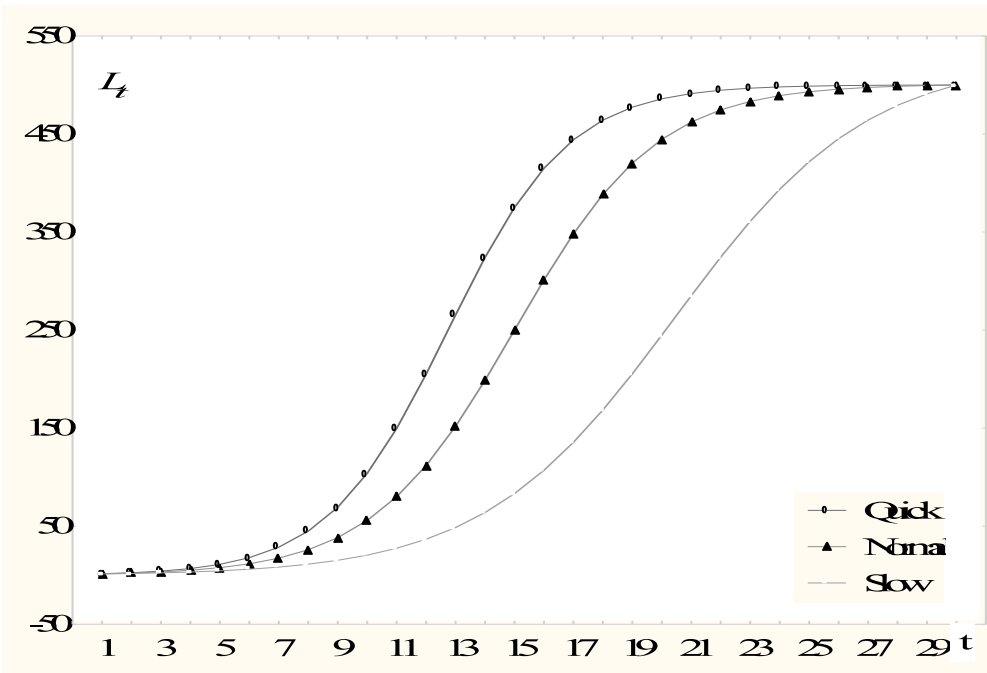

Figure 2. An illustration of temporal development patterns

Figure 2 is an example of three modes, where $L_{d}=500, n=30, \lambda$ is equal to $4 / 3,2$ and 4 respectively for the three patterns. However, iteration time $t(1 \sim n)$ in simulation is different from the real time: year $y(1 \sim m)$ such as $1993(y=0)$ and $2000(y=7)$. If let $L_{i}(y)$ denote the total growth of project $i$ until year $y$, a transition from $L_{i}(t)$ to $L_{i}(y)$ should be established as equation 11 .

$$
L_{i}(y)=h\left(L_{i}(t)\right) \quad y=1,2, \ldots m ; \quad t=1,2, \ldots, n ; n>m
$$


In previous research on CA applications, a linear function is applied, i.e. $t=\Delta^{*} y$. Here $\Delta$ is assumed to be a constant, which means equal growth rate. For example, when $y=5$ years, $t=20$ iterations, in the case of linear relationship, it can be defined as $\mathrm{t}=4^{*} \mathrm{y}$. So $\mathrm{y}(1)=\sum L(t), 0<t<5$. In reality, function $h$ could be a non-linear function of iteration number $t$, which can be tested experimentally through qualitative understanding and visual exploration of the difference between actual and simulated processes.

\subsection{A conceptual model for local temporal dynamics}

The multi-stage method can understand the global temporal dynamics of the whole study area rather than local dynamics of each project. The latter requires a different perspective focusing on more detailed spatial and temporal processes.

Heterogeneity in a temporal context means that the parameters describing any geographical phenomena vary from phase to phase in the whole period studied. For example, $\mathrm{Wu}$ and Yeh (1997) applied logistic regression methods for modelling land development patterns in two periods (1979-1987 and 1987-1992) based on parcel data extracted from aerial photographs. They found that the major determinants of land development have changed from distance from the city centre to closeness to the city centre; from proximity to inter-city highways to proximity to city streets; and are more related than less related to the physical condition of the sites. This suggests that various factors are changing their roles in the process of land development. Likewise, if we shrink the long period (1979-1992) to a shorter period such as 1993-2000 and zoom out the spatial extent from whole city to a smaller part such as a large-scale project, the same principle should be working as well. Therefore, temporal heterogeneity results in complex spatial and temporal process, which need to be identified in modelling. As similar patterns can result from numerous different processes, the understanding of process is more important than that of pattern. Pattern is only a phenomena but process is the essence. 


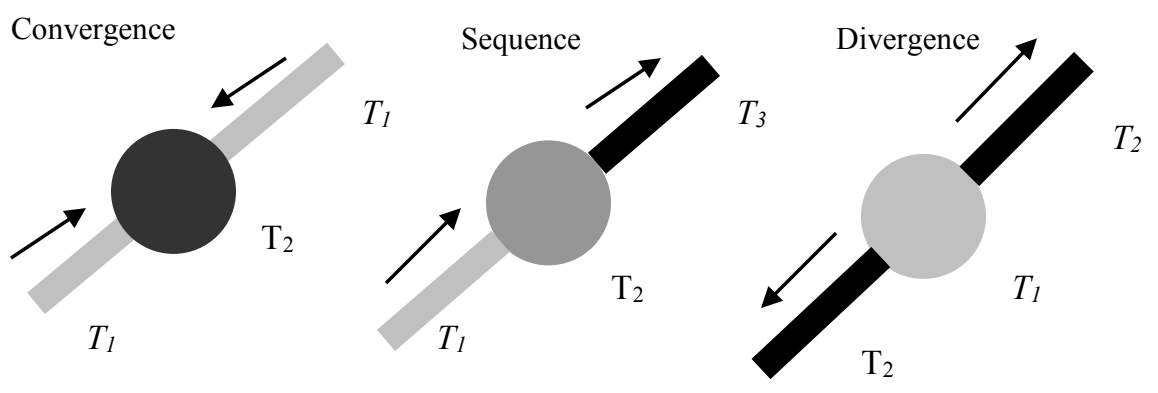

Figure 3. Different spatial-temporal process

Figure 3 is only an example of spatial pattern and processes involved in urban growth. $T_{1}, T_{2}, T_{3}$ indicate time series of land development. The grey level means the temporal order of land development. The same spatial pattern results from three (in reality, more) distinct spatialtemporal processes, which reflect the spatial and temporal interactions between road-influenced and centre-based local growth patterns. The arrows indicate the trend of temporal development, from which we can define them as three different processes (convergence, sequence and divergence).

The basic principle behind the phenomena is that various physical factors like road and centre take temporally varied roles in the course of local growth. In the first one (convergence), the road is more important than the centre at time $T_{1}$, but less important at $T_{2}$. This means that local growth occurs along the road first and then moves to the centre. The third one has an opposite effect. If we use $\mathrm{L}$ to denote the total amount of local growth, $\mathrm{L}_{l}$ for the lower part along road, $\mathrm{L}_{u}$ for the upper part along road, $\mathrm{L}_{c}$ for the centre part and $\mathrm{L}_{t}$ for the continuous development amount till time $t, \mathrm{~L}=\mathrm{L}_{l}+\mathrm{L}_{u}+\mathrm{L}_{c} . \mathrm{W}_{\mathrm{r}}$ and $\mathrm{W}_{\mathrm{c}}$ represent the weight value of spatial factor ROAD and CENTER respectively. The rules detected are listed in table 1 . The three cases imply that temporal dynamics could be represented and understood through the dynamic weighting concept. Dynamic weighting means that factor weight is not a constant but a function of temporal development amount (equation 12). 
Table 1. Dynamics in local spatial-temporal processes

\begin{tabular}{llll}
\hline Process & $T_{1}$ & $T_{2}$ & $T_{3}$ \\
\hline \multirow{2}{*}{ Convergence } & $\begin{array}{l}\mathrm{W}_{\mathrm{r}} \rightarrow 1, \mathrm{~W}_{\mathrm{c}} \rightarrow 0 \\
\left(\text { if } \mathrm{L}_{\mathrm{t}}<\mathrm{L}_{1}+\mathrm{L}_{\mathrm{u}}\right)\end{array}$ & $\begin{array}{l}\mathrm{W}_{\mathrm{r}} \rightarrow 0, \mathrm{~W}_{\mathrm{c}} \rightarrow 1 \\
\left(\text { if } \mathrm{L}_{\mathrm{t}}>\mathrm{L}_{1}+\mathrm{L}_{\mathrm{u}}\right)\end{array}$ & - \\
& $\mathrm{W}_{\mathrm{r}} \rightarrow 1, \mathrm{~W}_{\mathrm{c}} \rightarrow 0$ & $\mathrm{~W}_{\mathrm{r}} \rightarrow 0, \mathrm{~W}_{\mathrm{c}} \rightarrow 1$ & $\mathrm{~W}_{\mathrm{r}} \rightarrow 1, \mathrm{~W}_{\mathrm{c}} \rightarrow 0$ \\
Sequence & $\left(\right.$ if $\left.\mathrm{L}_{\mathrm{t}}<\mathrm{L}_{\mathrm{l}}\right)$ & $\left(\right.$ if $\left.\mathrm{L}_{\mathrm{t}}>\mathrm{L}_{\mathrm{l}} \& \mathrm{~L}_{\mathrm{t}}<\mathrm{L}_{1}+\mathrm{L}_{\mathrm{c}}\right)$ & $\begin{array}{l}\left.\text { (if } \mathrm{L}_{\mathrm{t}}>\mathrm{L}_{\mathrm{l}}+\mathrm{L}_{\mathrm{c}} \& \mathrm{~L}_{\mathrm{t}}<\mathrm{L}\right) \\
\text { Divergence }\end{array}$ \\
$\begin{array}{l}\mathrm{W}_{\mathrm{r}} \rightarrow 0, \mathrm{~W}_{\mathrm{c}} \rightarrow 1 \\
\left(\text { if } \mathrm{L}_{\mathrm{t}}<\mathrm{L}_{\mathrm{c}}\right)\end{array}$ & $\begin{array}{l}\mathrm{W}_{\mathrm{r}} \rightarrow 1, \mathrm{~W}_{\mathrm{c}} \rightarrow 0 \\
\left(\text { if } \mathrm{L}_{\mathrm{t}}>\mathrm{L}_{\mathrm{c}} \text { and } \mathrm{L}_{\mathrm{t}}<\mathrm{L}\right)\end{array}$ & - \\
\hline
\end{tabular}

Note: symbol " $\rightarrow$ " means "approaching to or close to"

$$
W_{i}(t)=f_{i}\left(L_{t}\right) \quad i=1,2
$$

To some extent, this equation suggests a dynamic feedback between $w_{i}(t)$ and $L_{t}$, representing the complex interaction between pattern and process. $L_{t}$ indicates the temporal pattern in amount, and the process is described by the changing roles of multiple factors $w_{i}(t)$; actually, $L_{t}$ is also impacted by $w_{i}(t)$. In principle, the functions $f_{i}\left(L_{t}\right)$ should be continuous, which can be a step linear or more complicated non-linear function as $w_{i}(t)$ is not negatively or positively linear to $L_{t}$ in most cases. For example, in the case of the sequence (table 1), $\mathrm{W}_{\mathrm{r}}$ temporally experiences a decrease from 1 to 0 and then an increase from 0 to 1 from $T_{1}$ to $T_{3}$. Apparently, $W_{r}$ is a nonlinear function of $L_{t}$. When $f_{i}\left(L_{t}\right)$ is constant in relation to $t, w_{i}$ is becoming universe temporally, as applied in most CA applications. However, this treatment is effective for understanding global dynamics in equation 3 but not local dynamics at project level illustrated in figure 3 . The design of function $f_{i}\left(L_{t}\right)$ is a critical point. Empirical study can be carried out based on a theoretical understanding of the interaction. Higher temporal resolution such as a series of actual value $L_{t}$ can be used to calibrate the temporal rules $w_{i}(t)$. In simplicity, the functions $f_{i}$ can be discretised. This implies that the whole period needs to be divided into a few phases $t_{1} \sim t_{n}$, in which varied weight values are defined with the assistance of local knowledge or by calibration from data. 


\section{Implementation}

Towards understanding the dynamic process of urban growth in a rapidly growing metropolitan region, a case study of Wuhan city, P.R.China is used for testing the methodology presented above.

\subsection{Wuhan context}

As the capital of Hubei Province, Wuhan is the largest megacity in central China and in the middle reaches of the Yangtze River (Figure 4). In 1999, it had an urban population of around 4 million, 4 times more than that of 1949. During the last 5 decades, Wuhan underwent rapid urban growth from 3,000 ha of built-up area in 1949 to 27,515 ha in 2000 . As a result, Wuhan is a good case for understanding the dynamic processes of urban growth in a fast developing country. In this paper, the urban growth of Wuhan in the period 1993-2000 will be modelled based on the methodology discussed in section 2 .

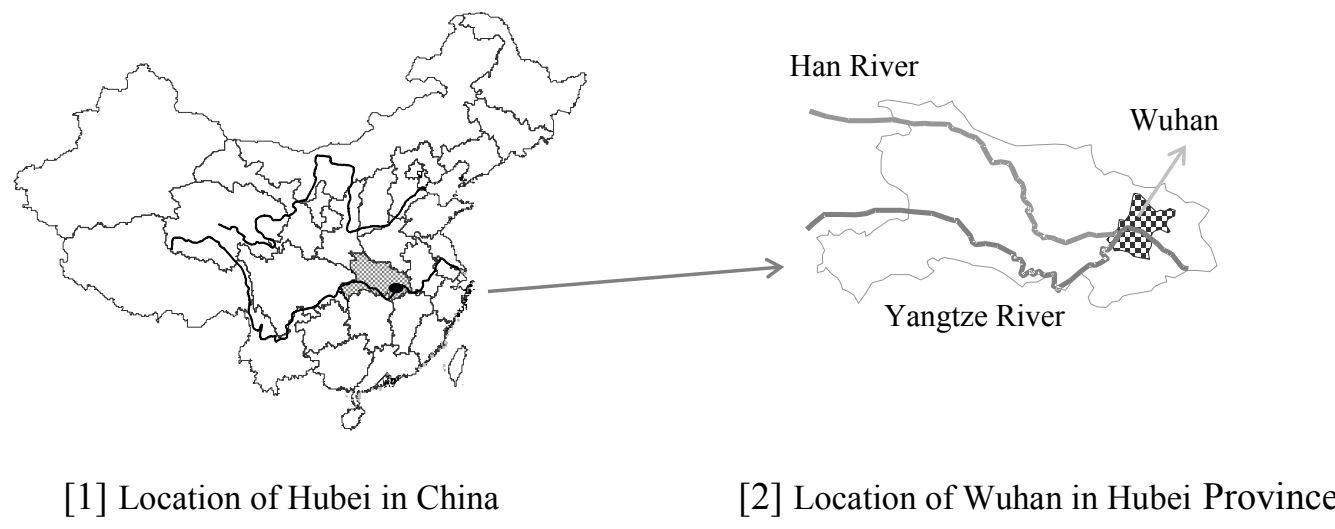

Figure 4. Location of Wuhan city

Operational CA models need access to real databases for better simulation performance(Li and Yeh, 2001).The imagery employed here includes SPOT PAN/XS of 2000, which covers the whole study area. The images are utilised as the primary data source for creating a land cover change map from 1993 to 2000. The topographic map (scale 1:10,000) of 1993 was used for imagery geo-coding registration and also for producing the land cover map of 1993 . The 
secondary sources include planning scheme maps, traffic/tourism maps, street boundary maps, and population census and statistical yearbook. They are used to create the required spatial factors (e.g. proximity and density variables) for CA modelling based on simple GIS operations such as overlay, buffering and neighbourhood statistics. The image processing for land cover mapping is implemented through ERDAS IMAGINE 8.4 package and on-screen digitising and spatial data analysis is carried out in ArcView environment (Cheng and Masser, 2003).

Table 2. Land cover transition from 1993 to 2000 (unit of area: $h a$ )

\begin{tabular}{lcllll}
\hline Major types & Waters & Town/Villages & Agricultural land & Others & Total \\
\hline Area in 1993 & 30,258 & 8,669 & 51,585 & - & - \\
Transited Area & 1,131 & 1,530 & 3,527 & 72 & 6,260 \\
Transition percent & $18.1 \%$ & $24.4 \%$ & $\mathbf{5 6 . 3 \%}$ & $1.2 \%$ & $100 \%$ \\
Annual Transition rate & $0.5 \%$ & $2.3 \%$ & $0.9 \%$ & - & - \\
\hline
\end{tabular}

Land cover transition from 1993 to 2000 is calculated based on a $10 * 10 \mathrm{~m}^{2}$ cell size and listed in table2. This table shows that major land use/cover changes come from waters, town/villages and agricultural land, which were physically or functionally transferred into the urban built-up area. Town/villages with the highest annual transition rate were only functionally transferred to urban administration due to the rapid expansion of Wuhan municipality. Agricultural land is the dominant one with the highest transition percentage. Here, the water body includes ponds and lakes. A higher percentage area is taken for transition from ponds than from lakes (see map of actual pattern in figure 6). The item 'Others' includes green areas, sands, and mis-classification from images processing etc, which is omitted for modelling.

\subsection{Project planning and site selection}

With assistance from historical documents, local planners and fieldwork, four large-scale projects, which were planned before or around 1993 were identified (WBUPLA, 1995). All 
small-scale projects were merged into one class, which results in five projects (Figure 6 and table 3) as follows:

1) Zuankou: car manufacturing plant (planned from 1988);

2) Wujiashan: Taiwanese investment zone (planned from 1992);

3) Guanshan: hi-tech development zone (planned from 1988);

4) Changqing: large-scale residential zone (planned from 1994);

5) The rest: small-scale development (commercial/institutional/residential).

In a GIS environment (ArcView 3.2a), we create the required spatial layers (figure 5) including land cover of 1993, distance to road networks and city centres/sub-centres, master plan (19962020), and population density. These layers are exported into a computational program for testing different site selection rules for each project according to equation 2. As a result of a sensitivity analysis conducted in a visual programming environment, the tested constraints at three levels for each project are listed in table 3. The total amount of development $L_{d}$ (from the actual urban growth in figure 6) and the temporal control mode (from document and interviews) are also displayed in this table. After 1992, Wuhan entered a new wave of development characterised by more actors, diverse functions and new industry structure (Cheng and Masser, 2003). From this table, we are able to explain the spatial behaviour of the actors involved in each project. For instance, the dominant actor in Zuankou, Wujiashan and Guanshan projects is Wuhan municipality, which obtained financial resources from the central government, foreign investors and local enterprises. Being the owner of the land, the actor did not need to consider the costs of land utilisation. Hence, for large-scale projects, the first rule is the availability of a certain amount of developable land. Being manufacturing and tertiary industry oriented, the second rule is accessibility to major road networks. Strictly speaking, the second one is not only true for largescale but also for small-scale land development such as commercial use. 
Table 3. Site selection rules of five projects

\begin{tabular}{|c|c|c|c|c|c|}
\hline Project & Zuankou (1) & Wujiashan (2) & Guanshan (3) & Changqing (4) & The Rest(5) \\
\hline Cells - $L_{d}$ & 1,390 & 314 & 514 & 160 & 3,710 \\
\hline Functions & Manufacturing & Economic zone & High-tech zone & Residential & Mixture \\
\hline $\begin{array}{c}\text { Global } \\
\text { constraints }\end{array}$ & $\begin{array}{l}<300 \mathrm{~m} \text { to } \\
\text { major road }\end{array}$ & $\begin{array}{c}<300 \mathrm{~m} \text { to major } \\
\text { road }\end{array}$ & $\begin{array}{l}<300 \mathrm{~m} \text { to major } \\
\text { road; } \\
<4.2 \mathrm{~km} \text { to the } \\
\text { university street }\end{array}$ & $\begin{array}{c}<300 \mathrm{~m} \text { to major } \\
\text { road; } \\
<3.5 \mathrm{~km} \text { to } \\
\text { sub-centres; } \\
>560 \text { (person/ha) } \\
\text { in net population } \\
\text { density. }\end{array}$ & $\begin{array}{c}\text { Close to city } \\
\text { centres/sub } \\
\text { centres; } \\
\text { Close to road } \\
\text { network. }\end{array}$ \\
\hline $\begin{array}{l}\text { Regional } \\
\text { constraint }\end{array}$ & $\begin{array}{c}\text { Density of } \\
\text { developable land } \\
>62 \% \\
\text { in a } 4.5 \times 4.5 \mathrm{~km}^{2} \\
\text { square; } \\
\& \\
>90 \% \text { in a } 2 \times 2 \\
\mathrm{~km}^{2} \text { square }\end{array}$ & $\begin{array}{c}\text { Density of } \\
\text { developable land } \\
>69 \% \text { in a } 1 \times 1 \\
\mathrm{~km}^{2} \text { square; } \\
\text { Density of } \\
\text { developed area } \\
>18.7 \% \text { in a } 2 \times 2 \\
\mathrm{~km}^{2} \text { square. }\end{array}$ & $\begin{array}{c}\text { Density of } \\
\text { developable land } \\
>68 \% \\
\text { in a } 3 \times 3 \mathrm{~km}^{2} \\
\text { square }\end{array}$ & $\begin{array}{c}\text { Density of } \\
\text { developable land } \\
>60 \% \text { in a } 1 \times 1 \\
\mathrm{~km}^{2} \text { square; } \\
\text { Density of } \\
\text { developed area } \\
>10 \% \text { in a } 2 \times 2 \\
\mathrm{~km}^{2} \text { square }\end{array}$ & $\begin{array}{l}\text { Higher } \\
\text { density of } \\
\text { developed } \\
\text { areas }\end{array}$ \\
\hline $\begin{array}{c}\text { Local } \\
\text { constraint }\end{array}$ & $\begin{array}{l}\text { Agricultural, } \\
\text { village }\end{array}$ & $\begin{array}{l}\text { Agricultural, } \\
\text { village }\end{array}$ & $\begin{array}{l}\text { Agricultural, } \\
\text { village, hill }\end{array}$ & Agricultural, pond & $\begin{array}{l}\text { Agricultural, } \\
\text { village, pond, } \\
\text { lake }\end{array}$ \\
\hline $\begin{array}{c}\text { Temporal } \\
\text { control }\end{array}$ & Quick & Slow & Quick & Quick & Normal \\
\hline
\end{tabular}

Moreover, the accessibility to developed areas is very crucial for the economic development zone (Wujiashan) and the high-tech zone (Guanshan). Access to research resources including nearly 20 universities is a prerequisite to locating a high-tech zone (Guanshan). In contrast, the major actors in Changqing housing project are local real estate companies and relevant work units. Land value is becoming an important criteria, which weakens the role of accessibility to the city centres. Low quality land cover such as ponds is much cheaper than agricultural land. Higher population density can guarantee better market demand as an influential factor for residential development. For small-scale projects especially inside urban districts, more actors are involved in the decision-making including local residents, investors, work units, planners, and the lower 
levels of local government. This results in a more stochastic process of site selection as a result of which the constraints become more uncertain and fuzzy. However, generally speaking, accessibility to the city centre/sub-centre and road networks is the key factor.

\subsection{Local growth}

The cell size in this research is $100 \times 100 \mathrm{~m}^{2}$, which results in a $640 \times 410$ grid. A smaller cell size (such as $10 \times 10 \mathrm{~m}^{2}$ ) would cause an overload in terms of model computation. The state of cells is binary (1-change, 0-nonchange). The initial layer is the 1993 land cover. This includes Developed, Agricultural (A), Village/town (V), Pond (P), Lake (L), and Protected (Green, Park, and Sands). In figure 5a, P and L are merged into water bodies, and 'others' include protected. As described in 3.1, only 4 types A, V, P and L underwent much change. As explored by the pattern model from another part of this research (Cheng and Masser, 2003), the major spatial determinants of urban growth in 1993-2000 included major road networks, minor road networks, centres/sub-centres and master planning, as displayed in figure 5. They are selected here as nonconstrictive factors for evaluating the potential for land conversion.

It should be noted that the classification of each layer is of great importance and modelling is sensitive to the classification particularly when the study area is large and the period is long. For instance, the construction of roads may occur in different phases of the period to be modelled. Their construction time should be taken into account. In this research, a major road connection (linking with the third bridge over the Yangtze River) was completed in early 2000. This is clearly visible in the 2000 SPOT images. However, this major road is not be included in the major road network layer because it had no practical impacts on urban development in the period 1993-2000. This judgement is also confirmed by very sparse and limited land cover change surrounding the road. Other layers are spatially defined by following similar rules. 
Wuhan city can be treated as a flat landscape as its elevation ranges between $22 \sim 27 \mathrm{~m}$ above sea level in addition to few hills. Hence, slope is not an influential factor. Physical constraints principally comprise water bodies (see figure 5a). Theoretically, water bodies should be completely excluded. However, in this case study, $18 \%$ of the land cover change comes from water bodies, which include ponds and lakes (see table 2). As this comes mostly from either small-scale ponds or the fringe of large lakes, a general procedure can be designed for defining a specific layer (Exclusion Layer):

- $\quad$ Extracting a water body from the land cover layer of 1993;

- Neighbourhood statistics (based on a circular neighbourhood with a 200-m radius);

- Selecting sum $>4$ (neighbouring 4-ha area are also water)

The layer will be utilised as physical constraint from the water body, defining excluded zones from transition.

In the five CA models corresponding to five projects, a circular neighbourhood is chosen because it does not have significant directional distortion. Its size varies with different projects, ranging from 3 to 9 cells. The selection of neighbourhood size for each project relies on empirical study and sensitivity analysis (see a later section). The heterogeneity of spatial processes is indicated by varied combination of influential factors, weight values and parameters, which imply distinguishing local spatial behaviour.

Given that local growth is impacted by the master plan to be implemented in this period, we must incorporate the master plan for 1996-2020 as an influential factor (this scheme was initiated in 1990 and approved by the Central Government in 1996). Due to the rapid urban expansion in the fringe, some projects such as Changqing, Wujiashan had not even been planned until their construction. These will be excluded from the master planning analysis. Only the projects covered by master planning are considered i.e. Guanshan, Zuankou and The Rest. Each cell is assigned with a value $P_{\mathrm{i}}$, representing the influential degree of the planned land use $i$ on land 
cover transition in a project. If let $M_{i}$ denotes the total area of land use $i$ in a specific project, $C_{i}$ denotes the transited part of $M_{i}, P_{\mathrm{i}}=C_{i} / M_{i}$. The $P_{i}$ value of major land uses is listed in table 4 . This code follows the National Urban Land-use Classification Standard (NULCS). In figure 5d, 'Residential' includes $R_{1}-R_{3}$, 'Green' $G_{1} \sim G_{3}$, 'Street' $S_{1}$, the rest $\left(C_{1}, C_{3}, C_{4}, C_{5}\right)$ are all merged into 'Others'. $P_{\mathrm{i}}$ needs to be standardised according to $P_{i} / \max \left(P_{i}\right)$ before it can be incorporated into the evaluation formula (equation 3). Generally, table 4 reveals that the master plan was more successful in guiding large-scale projects in the fringe than small-scale ones in urban districts.

Table 4. Influential degree of master planning on land cover transition

\begin{tabular}{llllllll}
\hline Code & Classification & \multicolumn{2}{c}{ Zuankou } & \multicolumn{2}{c}{ Guanshan } & \multicolumn{2}{c}{ The Rest } \\
& & $P_{\mathrm{i}}$ & $M_{\mathrm{i}}$ & $P_{\mathrm{i}}$ & $M_{\mathrm{i}}$ & \multicolumn{1}{c}{$P_{\mathrm{i}}$} & $M_{\mathrm{i}}$ \\
\hline R1 & Low-rise residential & 0.237 & 265 & 0.23 & 57 & 0.087 & 1082 \\
R3 & Poorer environment & - & - & - & - & 0.1333 & 149 \\
M & Industry & 0.318 & 508 & 0.24 & 172 & 0.049 & 419 \\
G1 & Public green & 0.27 & 137 & - & - & 0.0916 & 416 \\
G2 & Protected land & 0.147 & 58 & 0.33 & 112 & 0.041 & 222 \\
G3 & Ecological agriculture & - & - & - & - & 0.0216 & 82 \\
C1 & Administration/Offices & 0.26 & 52 & - & - & 0.0787 & 17 \\
C3 & Cultural/Recreational & 0.528 & 16 & - & - & - & - \\
C4 & Sports facility & - & - & 0.3 & 44 & 0.035 & 89 \\
C5 & Hospital/Health & 0.742 & 33 & - & - & - & - \\
S1 & Street & - & - & - & - & 0.069 & 354 \\
\hline "-": $\mathrm{M}_{\mathrm{i}}<15$ (omitted) & & & & & &
\end{tabular}

The calibration of parameters has proven to be a difficult task in urban CA modelling (Clarke and Gaydos, 1998; Li and Yeh, 2001) particularly when there are many factors and parameters to be considered. The difficulty lies in the fact that most urban CA modelling takes the whole municipality into calibration procedure, which results in intensive computation overload. In this research, project-based CA modelling has largely reduced the computational time of calibration as the spatial extent of project is much smaller than the whole study area as shown in table 5 and figure 6 .

The factors and parameters for model calibration includes six spatial factors, neighbourhood size and stochastic disturbance $\alpha$. Other parameters (e.g. temporal pattern mode $\lambda$, iteration time $t$ ) are utilised for sensitivity analysis in section 4.1. Six spatial factors are "distance to minor road" 
(OR), "distance to major road"(MR), "distance to centre/sub-centres"(CN), "density of neighbouring developed areas"(DD), "density of neighbouring new development" (DN), and "master planning". Their gradient of density $\phi$ (in equation 4) are taken from the global pattern model of logistic regression carried out in the another part of this research (Cheng and Masser, 2003). Automatic search for the best-fit parameters is carried out by using a hierarchical means i.e. to reduce step size for five loops corresponding to six factors at two stages. For example, the step size of loops in calculating the weight values is set as 0.05 first, i.e. from 0.05 to 1 step 0.05 . When the parameter scope of the ideal accuracy is determined, e.g. from 0.2 to 0.25 , we can set a second step size 0.005 for finer calibration, i.e. from 0.2 to 0.25 step 0.005 .

The validation accuracy depends on the approach used to compare simulated and actual patterns. This is traditionally measured by a coincidence matrix generated by a cell-cell comparison of two pattern maps. Some researchers argue that CA simulations should not be assessed just on the goodness of fit (a cell by cell basis) but also on their feasibility and plausibility as urban systems are rather complicated and their exact evolution is unpredictable (Yeh and Li, 2001). Some global measures that have been used for testing the validity of CA simulation, include the fractal and Moran I index (Wu, 1998), fractal analysis (Yeh and Li, 2001), and landscape metric (SoaresFilho et al., 2002). Wu (2002) emphasises the need to validate the model through both structural and cross-tabulation measures. Structural measures can only compare pattern (outcome of process) not the spatial location (or process). We consider that spatially location match is also of great importance for supporting planning decision making despite the difficulties imposed by CA modelling. Another reason lies in the fact that local processes at the project level require more accurate cell-based measure, as their morphology is less definite compared with those at the global level.

Clarke and Gaydos (1998) outline four ways to statistically test the degree of historical fit (three r-squared fits and one modified Lee-Sallee shape index). For the Lee-Sallee shape index 
(combining the actual and the simulated distributions as binary urban/non-urban, and computing the ratio of the intersection over the union), they reported that the practical accuracy is only 0.3 .

Table 5. CA Simulation of five projects

\begin{tabular}{|c|c|c|c|c|c|c|c|}
\hline Projects & Zuankou-1 & Zuankou-2 & & Wujiashan & Guanshan & Changqing & Rest \\
\hline Land demand $L_{d}$ & 1390 & 1390 & & 314 & 514 & 160 & 3710 \\
\hline Accuracy $C C$ & $54 \%$ & $54 \%$ & & $51.6 \%$ & $53.2 \%$ & $85 \%$ & $55 \%$ \\
\hline Lee-Sallee Index & 0.37 & 0.37 & & 0.35 & 0.36 & 0.74 & 0.38 \\
\hline Neighbourhood Size & 6 & 6 & & 5 & 8 & 3 & 7 \\
\hline$\lambda$ & $4 / 3$ & $4 / 3$ & & 4 & $4 / 3$ & $4 / 3$ & 2 \\
\hline Dynamic weighting & - & $<15 \% 15-55 \%$ & $>55 \%$ & - & - & - & - \\
\hline Major road (MR) & 0.2 & $\begin{array}{ll}- & 0.5\end{array}$ & 0.05 & 0.325 & 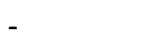 & 0.1 & 0.3 \\
\hline Minor road (OR) & 0.3 & 0.1 & 0.15 & 0.1 & 0.35 & 0.55 & 0.15 \\
\hline Centres (CE) & - & 0.7 & 0.5 & - & - & - & 0.2 \\
\hline Neighbourhood-new & 0.3 & 0.3 & 0.15 & 0.3 & 0.35 & 0.35 & 0.1 \\
\hline Neighbourhood-old & - & - & - & 0.275 & 0.25 & - & 0.2 \\
\hline Master Planning & 0.2 & 0.3 & 0.15 & - & 0.05 & - & 0.05 \\
\hline Total & $100 \%$ & $100 \%$ & $100 \%$ & $100 \%$ & $100 \%$ & $100 \%$ & $100 \%$ \\
\hline
\end{tabular}

Note: $\alpha=1 \%, \mathrm{n}=50$, Gradient for MR, OR and CN: $0.000765,0.0012$ and 0.000272

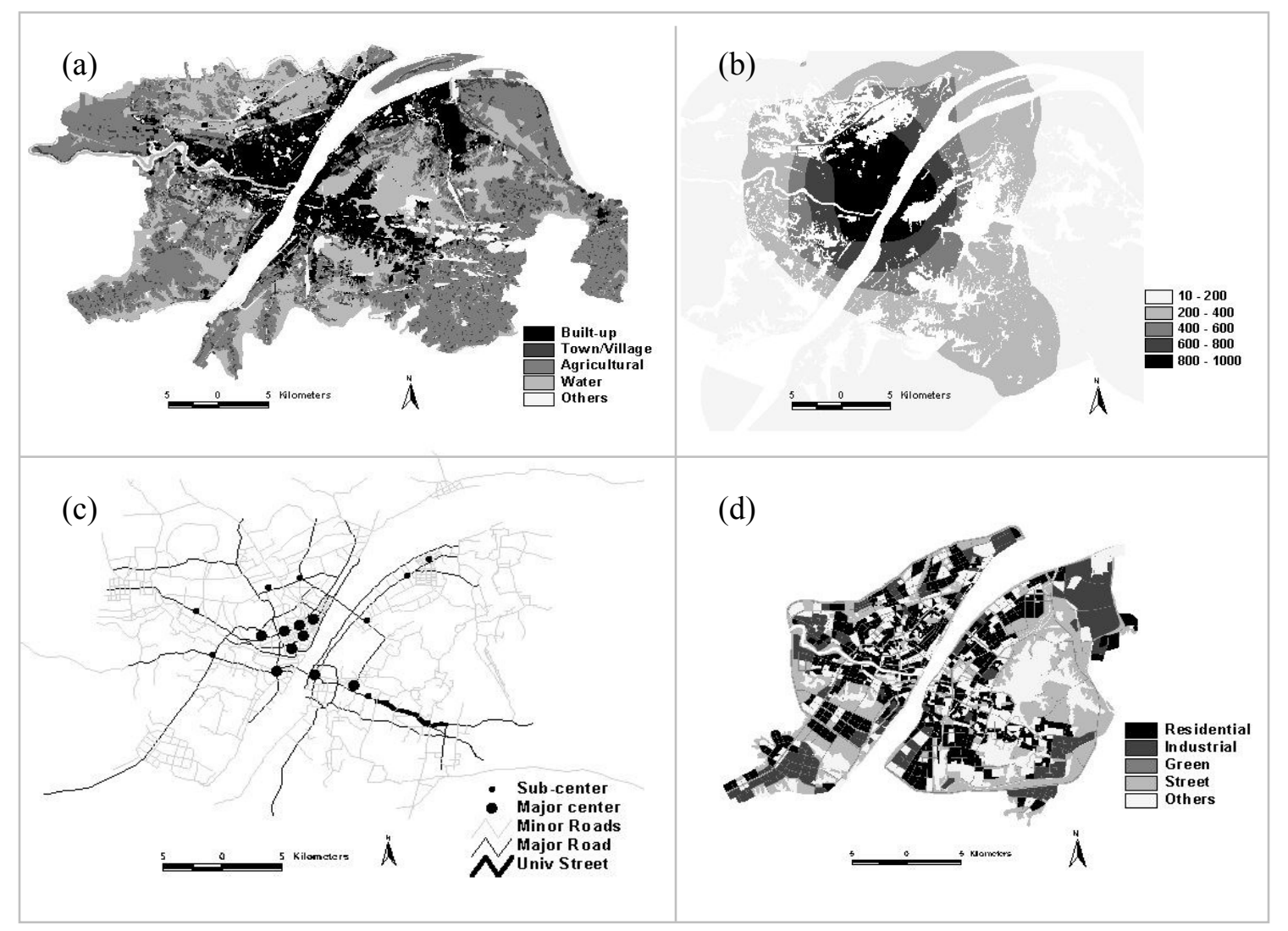

Figure 5. Spatial factors and constraints for site selection and CA modelling, a) land cover of 1993 ; b) population density (persons/ha); c) road networks and centres/sub-centres; d) master plan 1996-2020. 
In this paper, we use consistency coefficients $(C C)$ (the percentage of the matched over the actual) and the Lee-Sallee index $(L I)$ for the evaluation of goodness of fit. As the total number of pixels is set the same for simulation as the actual pattern, i.e. $L_{d}=L_{n}$. as such $L I=C C /(2-C C)$. For example when $C C=0.57, L I=0.4$. Following this formula, the Lee-Sallee index for 5 projects are computed and listed in table 5. The overall accuracy based on the weighted combination $\left(L_{d}\right)$ of 5 projects, is 0.554 in $C C$ and 0.383 in $L I$, greater than Clarke's.
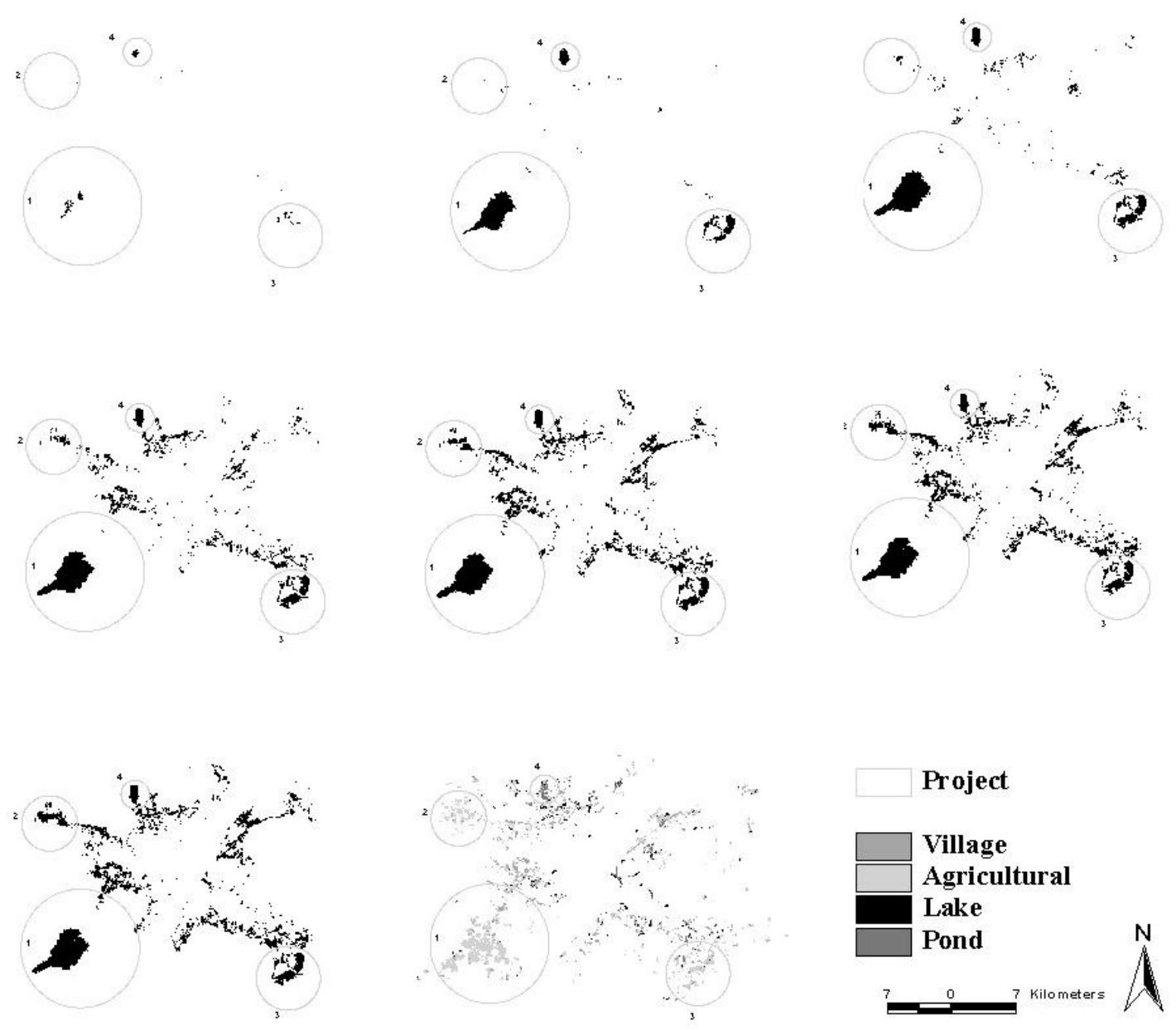

Figure 6. Simulated (1994-2000 in order) and actual patterns (last map) 


\subsection{Temporal control}

With local knowledge, we are able to identify the patterns of temporal development of each project (see table 3). In 1993, Zuankou was still completely rural. By 1995 it was nearly half constructed. There was not much change from 1997 and 2000. Therefore, its temporal growth pattern is defined as "Quick". The small-scale projects (the Rest are a mixture of all three patterns. Some may be quick and others slow. On average, it is reasonable to classify them as "Normal". The number of iterations is defined as $n=50$ because the greater the number the finer discriminative capacity of the models.

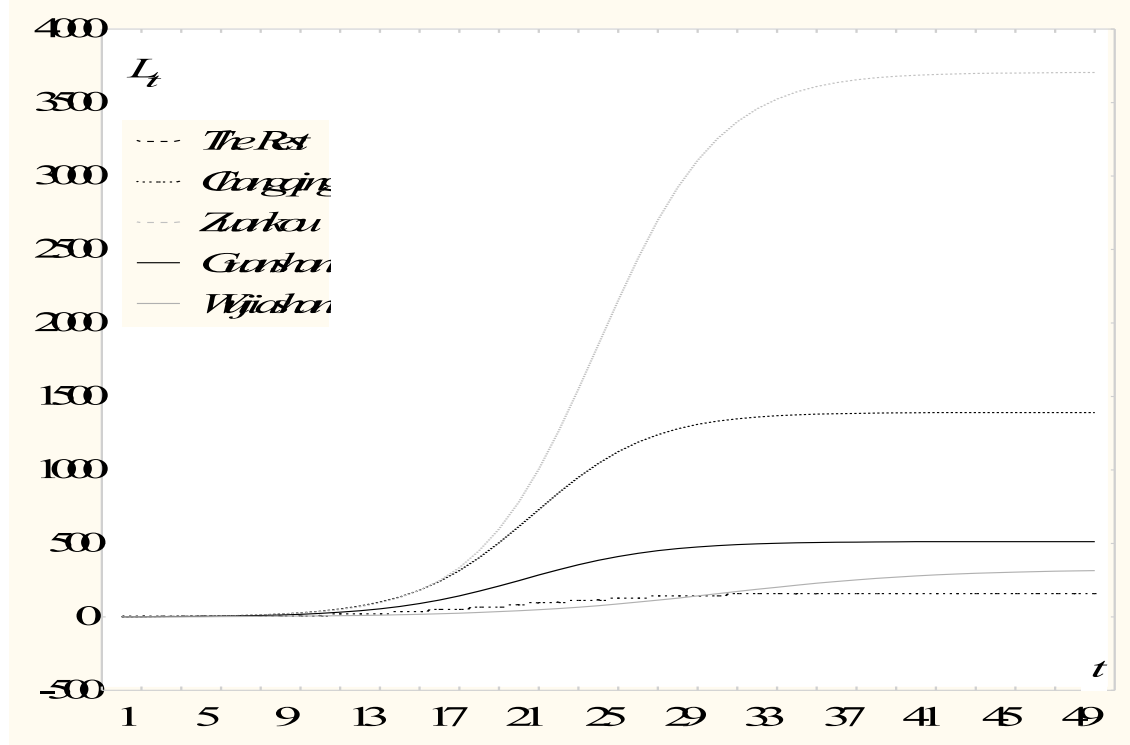

Figure 7. Temporal control patterns of five projects

Figure 7 exhibits the trajectories of temporal development of the five projects respectively, according to the results of the validated CA simulation. As described in equation 12, the output of CA simulation is $L_{i}(t)(1 \sim n)$, which is different from yearly actual amount $L_{i}(y)(1 \sim m)$ for each project $i$. We need a transition from $L_{i}(t)$ to $L_{i}(y)$. The transition function $h$ in equation 12 should be based on an understanding of the actual temporal development process, which is determined by its socio-economic development. For the sake of simplicity, we use an equal time interval, i.e. 
a linear function: $y=t / 7$. $A$ s $t$ ranges from 1 to $50(\mathrm{n}=50)$ and $y$ from 1 to $7(\mathrm{~m}=7), L_{i}(y)=$ $\Sigma L_{i}(t), t$ from $7^{*}(y-1)+1$ to $7^{*} y$. A series of new created layers of the whole study area corresponding to the 7-year urban growth (from 1993 to 2000, figure 6) have been imported into animation software (Animagic32) for dynamic visualisation. This animation is helpful for exploring and comparing the temporal dynamics of spatial processes.

Table 5 shows the spatial heterogeneity of the causal factors, which vary spatially in terms of their weight values. The neighbourhood effect is represented by neighbourhood size, and the weight values of new and old developed areas. This table suggests that there are some similarities and some dissimilarity between the five projects. The weight values of the major roads, minor roads, city centre/sub-centres and master planning also show some differences. Major roads play a greater role in "The Rest" and Wujiashan, and less important roles in Changqing, and Guanshan. Conversely, minor roads play a greater role in the latter projects than the former ones. By linking the site selection rules shown in table 3, it can be seen that the road networks system actually takes varying roles during different phases of urban growth. The major road network is the key at the stage of site selection and remains important for some areas at the stage of local growth. However, the minor road network is only active at the stage of local growth. This is due to the fact that minor road networks are created after the stage of site selection together with the new growth. Relatively, city centres/sub-centres are influential only for "The Rest" as the others are located in the urban fringe. Master planning is less influential than others. The spatial heterogeneity described above suggests that the casual-effects of urban growth vary from place to place. Local process modelling can offer deeper insights into urban growth processes.

\subsection{Local temporal dynamics}

Local temporal dynamics are focused on each project and are indicated by the following examples: 
- Compared with the major road network, minor roads, especially in new zones which are also new development units, may occur temporally at different phases of the period studied, i.e. between $T_{0}$ and $T_{n}$, but not immediately from $T_{0}$;

- The spatial impacts of various factors such as roads and centres are not simultaneous in temporally affecting local growth;

- Neighbourhood effects may suffer from temporal variation. For example, it may be stronger at $T_{0}$ than at $T_{n}$, or vice versa.
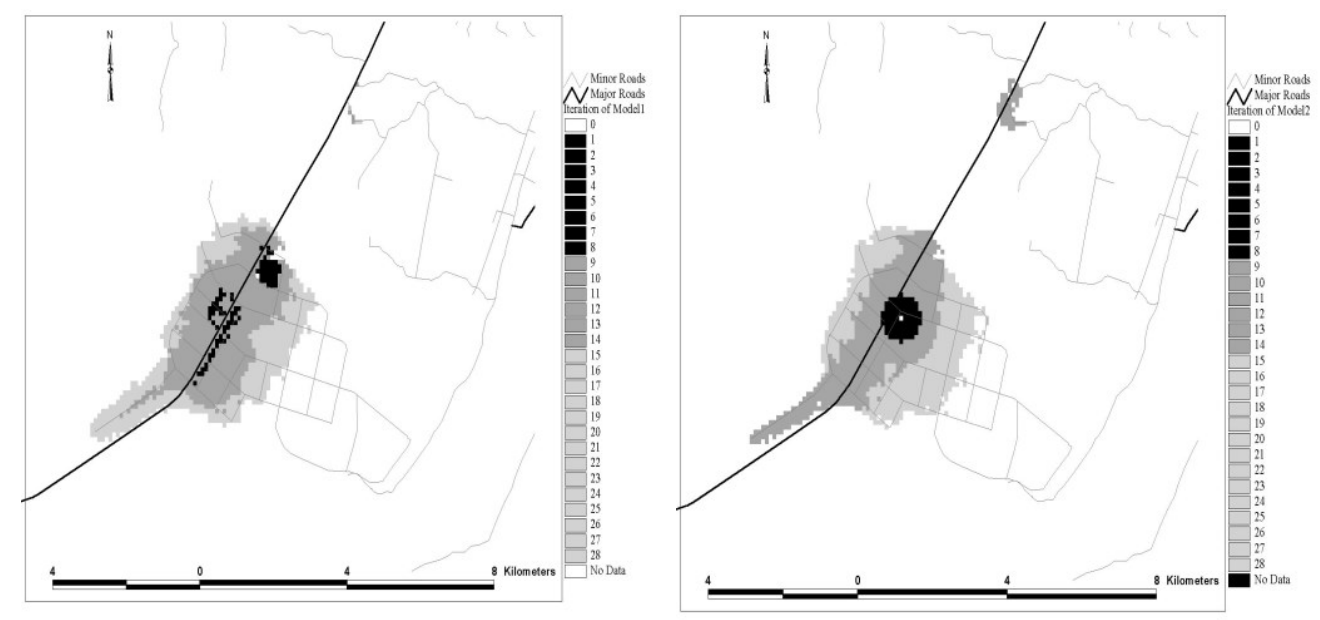

Figure 8. Local temporal dynamics (Zuankou-1 and -2 in table 5)

These examples qualitatively show the complex pattern and process interaction as explained in section 2.4. Two models of Zuankou in table 5 have similar model accuracy and similar patterns. However, their spatial-temporal processes are quite different as quantitatively shown in figure 8 . Model 1 exhibits a more random process. Model 2 shows a more self-organised process. Model 2 is based on the assumption that new development in Zuankou first occurred in the centre, then along the major road and finally spread from the centre. The assumption corresponds to a temporal dynamics that is spatially controlled by three sets of weight values (table 5). To calibrate this process-oriented CA model, the manual tests based on the modeller's understanding of local growth processes and the visual exploration of model outputs (temporal patterns) are very 
important for reducing parameter ranges and making rough estimates of dynamic weight values. Limited automatic search can be followed for the best ideal combination of parameters.

To some extent, the dynamic weighting implies the temporal lag of the spatial influences of locational factors on urban growth. This example suggests that local temporal dynamics can enable us to better understand the organised local growth. If we explore the changes in weight values, it can be found that the major changes are indicated in major roads and centres. As explained in equation 13, the weight values should be non-linear functions of temporal land development demand. Table 5 also shows the functions are highly complex in reality. They are frequently phased. Model 2 is actually based on local knowledge. Other projects can be calibrated temporally by the same procedures as in the Zuankou project.

\section{Discussion and Conclusions}

\subsection{Model calibration and validation}

Li and Yeh (2001) report a calibration procedure of CA modelling by using artificial neural network. In their method, a neural network is utilised to obtain the optimal parameter values automatically based on training empirical data and then the parameter values calibrated are used to carry out CA simulation for new data. In CA models of this kind, the transition rules represented by the neural network structure are not transparent to users. Consequently, this method can be used for prediction by using the same set of rules, but it is not ideal for interpreting the logic of land conversion or spatial-temporal processes as it is a black box (Wu, 2002).

It has been found in this research that visual tests offer a useful and quick way of calibrating and verifying a CA model (Clarke et al., 1997; Ward et al., 2000) particularly with respect to sensitivity analysis. In this project-based CA modelling, calibration has proven not to be a severe problem in computation time. However, the optimal combination of parameters from automatic search may not give the best results as socio-economic systems essentially produce no best solution. Consequently, the calibrated results need further confirmation according to the 
interpretation and plausibility of their spatial and temporal processes. In table 6, the Wujiashan project is taken as an example to illustrate this issue. When neighbourhood size is set as 5 , the optimal parameters with accuracy $52.8 \%$ are calculated from automatic search (step of weight value is 0.005), together with the other combination of parameters. However, the spatial processes produced by the weight values $(0.2,0.1,0.45,0.25)$ are not the same as the real temporal pattern based on visual comparison. Conversely, another combination $(0.325,0.1$, $0.3,0.275)$ can create more satisfactory temporal patterns although its model accuracy $(51.6 \%$ in $\mathrm{CC}$ ) is lower. Consequently, visual tests are still a necessary means for process rather than pattern modelling.

Table 6. Calibration of CA modelling and sensitivity analysis (Wujiashan project)

\begin{tabular}{llllllllll}
\hline Accuracy $C C$ & $52.8 \%$ & $\mathbf{5 1 . 6 \%}$ & $51.3 \%$ & $50.8 \%$ & $29.5 \%$ & $46 \%$ & $49.7 \%$ & $50 \%$ & $50.8 \%$ \\
\hline Neighbourhood size & 5 & $\mathbf{5}$ & 5 & 5 & 5 & 8 & 6 & 4 & $5(\lambda=4.5)$ \\
Major road (MR) & 0.2 & $\mathbf{0 . 3 2 5}$ & 0.325 & 0.225 & 0.375 & 0.1 & 0.325 & 0.325 & 0.325 \\
Minor road (OR) & 0.1 & $\mathbf{0 . 1}$ & 0.05 & 0.25 & 0.3 & 0.3 & 0.1 & 0.1 & 0.1 \\
Neighbourhood (new) & 0.45 & $\mathbf{0 . 3}$ & 0.35 & 0.15 & 0.3 & 0.4 & 0.3 & 0.3 & 0.3 \\
Neighbourhood (old) & 0.25 & $\mathbf{0 . 2 7 5}$ & 0.275 & 0.375 & 0.025 & 0.2 & 0.275 & 0.275 & 0.275 \\
Total & $100 \%$ & $\mathbf{1 0 0} \%$ & $100 \%$ & $100 \%$ & $100 \%$ & $100 \%$ & $100 \%$ & $100 \%$ & $100 \%$ \\
\hline
\end{tabular}

Note: $\alpha=1 \%, n=50, \lambda=4$, Gradient for MR, OR and CN: $0.000765,0.0012$ and 0.000272

Another part of calibration is sensitivity analysis as the results of CA simulation are very sensitive to the parameter values (e.g. neighbourhood size, weight values, $\lambda$ and $n$ ). This is the issue of uncertainty existing in CA simulation that has not been given enough attention in most applications. For the Wujiashan project, before accepting $(0.325,0.1,0.3,0.275)$, we need to test its stability by slightly or greatly adjusting the weight values and the other parameters such as neighbourhood size as listed in table 6 . The changes (slight or great) in validation accuracy that is identical to those in parameters assure the reliability of this set. 


\subsection{Visualisation of processes}

To implement site selection and CA modelling, a loose coupling strategy is frequently adopted for various applications (Clarke and Gaydos, 1998; Bell et al., 2000). Loose coupling means that a data transfer procedure is frequently implemented between a CA model, GIS, and an animation module. This loose-coupling strategy sacrifices the friendly interface but improves the computation efficiency of CA simulation. Here the site selection rules and the CA model is programmed in object-oriented programming language. Spatial data analysis and visual exploration tasks are implemented under a GIS environment - ArcView platform. Each layer produced is exported as an ASCII raster file. A sub procedure is programmed to read and write the ASCII raster files between CA and ArcView. The major parameters include the weight values, the temporal pattern control $\lambda$, the neighbourhood size and the stochastic perturbation $\alpha$. The validation results are automatically stored into a text file and an ASCII raster file. A validated urban growth layer (1993-2000) from the simulation is separated into a series of maps, each corresponding to one year. The layers created are exported as a JPG or any other type of image file. These are inserted as an individual frame into the animation file for visual check of spatial process. However, a major deficiency of this strategy is that it is not a very friendly environment for the immediate visualisation of spatial-temporal processes although it is effective for model calibration. In the future, CA modelling tightly coupled with GIS and animation should be further studied to enhance its visualisation function of spatial-temporal processes.

\subsection{Importance of local knowledge}

We cannot ignore the fact that any advanced modelling technique including CA must be based on a proper understanding and abstraction of the systems studied. The better the understanding the more accurate it is likely to be. Planning will never be a hard science, for it is built on humanistic assumptions, values and goals (Shmueli, 1998).Our understanding of the new urban reality will be ultimately based upon a combination of computers and human judgement (Sui, 1998). 
CA is only a simulation tool for testing a decision-maker's understanding. Limited by existing GIS theory and methods, the identification of various spatial and temporal heterogeneity cannot be completed without the assistance of local knowledge. This implies that local knowledge is an important ancillary data source for CA modelling especially under the framework presented in this paper. During the process of the modelling, project planning and temporal control needs more input from local experts. For dynamic weighting, due to the limited temporal resolution, local knowledge is an essential source of qualitative information. It has been stressed in this research that a soft-system methodology, stressing the roles of decision-makers, and feedback both between modellers and users and between stages of decision-making process is helpful especially when complete information resources are not guaranteed.

\subsection{Process modelling}

To some extent, the accuracy of a simulation model depends on the complexity and stochasticity of the real city and also on the availability of more detailed information. Although the overall accuracy of five CA models is only $55 \%$ based on a cell by cell basis, the methodology proposed in this paper illustrates the potential for understanding spatial processes and their temporal dynamics at the two levels based on the methodology. The spatial clustering of land development projects indicates a self-organising process. The timing schedule of various projects exhibits global temporal dynamics. Dynamic weighting is an important concept for simulating process rather than pattern. Spatial classification based on the project concept is subjective and transparent to urban planners. The spatial-temporal processes explored by project-based modelling can easily be interpreted with reference to socio-economic and decision-making processes. To be a true process model, CA modelling as suggested in this research should incorporate dynamic weighting methods although there is still much difficulty in systematically defining these functions in practice. 
From local spatial modelling point of view, a possible direction lies in applying a moving window or kernel in defining a project for each cell, so that generalised local process modelling can be repeatedly applied for each cell. This is a similar principle to that applied in geographically weighted regression (GWR) modelling. This idea can result in universally localised process modelling. The parameters for understanding local processes vary with the cell. Users can redefine interesting projects for further interpretation by focusing on some hot-spots.

From the perspective of spatial data analysis, the methodology can be utilised to discover the hidden processes from required integrated spatial database regarding temporal urban growth. This has been one of the major concerns in the field of spatial data mining or knowledge discovery. When socio-economic data at detailed levels become available, project-based CA modelling can be further linked with micro-scale multi-agent and economic modelling. Such integration can explore the spatial and economic behaviour of various actors at the micro scale.

The major purpose of CA simulation is to generate alternative scenarios for decision support in a smart growth management. The methodology developed here can be extended in this direction. In this new case, stages 1 and 4 need to incorporate top-down socio-economic models for predicting the demand for new land development in the future i.e. $L_{d}$ in equation 1 . Stage 2 and 3 are subject to some modification in quantification. The construction of plan scenarios is based on soft systems thinking, which stresses the role of users' subjectivity. In this way local planners' intentions can be transformed into spatially and temporally explicit weight values and certain parameters e.g.( $\mathrm{Wu}, 1998)$. With a user friendly visualisation environment, the framework tested in this research can facilitate decision- making of urban spatial development.

\section{Acknowledgement}

This research was financially supported by the DSO-SUS project between CHINA and the Netherlands. The authors gratefully thank all persons who assisted in collecting data. Thanks are 
also extended to three anonymous reviewers for their constructive and critical comments which helped create the current version.

\section{References}

Anas, A., 1982 Residential Location Markets and Urban Transportation: Economic Theory, Econometrics and Policy Analysis with Discrete Choice Models (Academic Press, New York)

Anselin, L., 1995, "Local indicators of spatial association - LISA" Geographical Analysis 27(2) $93-115$

Batty, M., 1998, "Urban evolution on the desktop: simulation with the use of extended CA" Environment and Planning A 30(11) 1943-1967

Batty, M.,Kim, K. S., 1992, "Form follows function: reformulating urban population density functions" Urban Studies 29 1043-1070

Batty, M.,Torrens, P. M., 2001, "Modeling complexity: the limits to prediction" CyberGeo (online journal) 201

Batty, M., Xie, Y.,Sun, Z., 1999, "Modelling urban dynamics through GIS-based cellular automata" Computers, Environment and Urban Systems 23 205-233

Bell, M., Dean, C.,Blake, M., 2000, "Forecasting the pattern of urban growth with PUP: a webbased model interfaced with GIS and 3D animation" Computers, Environment and Urban Systems 24 559-581

Benati, S., 1997, "A cellular automata for the simulation of competitive location" Environment and Planning B: Planning and Design 24 205-218

Besussi, E., Cecchini, A.,Rinaldi, E., 1998, "The diffused city of the Italian north-east: identification of urban dynamics using CA urban models" Computers, Environment and Urban Systems 22(5) 497-523

Cheng, J.,Masser, I., 2003, "Urban growth pattern modelling, a case study of Wuhan, P.R.China" Landscape and Urban Planning 62(4) 199-217 
Clarke, K. C.,Gaydos, L. J., 1998, "Louse-coupling a CA model and GIS: long-term urban growth prediction for San Franciso and Wanshington/Baltimore" International Journal of Geographical Information Science 12(7) 699-714

Clarke, K. C., Hoppen, S.,Gaydos, L., 1997, "A self-modifying cellular automaton of historical urbanization in the San Francisco Bay area" Environment and Planning B: Planning and Design $24247-262$

Couclelis, H., 1997, "From cellular automata to urban models: new principles for model development and implementation" Environment and Planning B: Planning and Design 24 165174

Dragicevic, S., Marceau, D. J.,Marois, C., 2001, "Space, time, and dynamics modeling in historical GIS databases: a fuzzy logic approach" Environment and Planning B: Planning and Design 28 545- 562

Fotheringham, S.,Rogerson, P., 1994 Spatial Analysis and GIS (Taylor \& Francis Ltd, New York)

Getis, A.,Boots, B., 1978 Models of Spatial Process: An Approach to the Study of Point, Line and Area Patterns (Cambridge University Press, London)

Gregory, I. N., 2002, "Time-variant GIS database of changing historical administrative boundaries: a European comparison" Transactions in GIS 6(2) 161-178

Herbert, D. T.,Thomas, C. J., 1997 Cities in Space: City as Place, 3nd edn (David Fulton Publishers, London)

Horita, M., 2000, "Mapping policy discourse with CRANES: spatial understanding support systems as a medium for community conflict resolution" Environment and Planning B: Planning and Design 27(6) 801-814

Li, X., Yeh, A. G.-O., 2001, "Calibration of cellular automata by using neural networks for the simulation of complex urban systems" Environment and Planning A 33 1445-1462 
Masser, I., 2001, "Managing our urban future: the role of remote sensing and geographic information systems" Habitat International 25 503-512

Muth, R., 1969 Cities and Housing: The Spatial Pattern of Urban Residential Land Use (Chicago University Press, Chicago, IL.)

Orjan, S., 1999, "Shortage, priority and urban growth: towards a theory of urbanisation under central planning" Urban Study 36(13) 2217-2236

Saaty, T. L., 1980 The Analytical Hierarchy Process: Planning, Priority Setting, Resource Allocation (McGraw-Hill, New York)

Shmueli, D., 1998, "Applications of neural networks in transportation planning" Progress in Planning 50 141-204

Silva, E. A.,Clarke, K. C., 2002, "Calibration of the SLEUTH urban growth model for Lisbon and Porto, Portugal" Computers, Environment and Urban Systems 26(6) 525-552

Soares-Filho, B. S., Coutinho-Cerqueira-G.,Lopes-Pennachin-C., 2002, "DINAMICA - A stochastic cellular automata model designed to simulate the landscape dynamics in an Amazonian colonization frontier" Ecological Modelling 154(3) 217-235

Sui, D. Z., 1998, "GIS-based urban modelling: practices, problems, and prospects" International Journal of Geographical Information Science 12(7) 651-671

Sui, D. Z.,Hui, Z., 2001, "Modeling the dynamics of landscape structure in Asia's emerging desakota regions: a case study in Shenzhen" Landscape and Urban Planning 53 37-52

Torrens, P. M.,O'Sullivan, D., 2001, "Cellular automata and urban simulation: where do we go from here?" Environment and Planning B: Planning and Design 28 163-168

Ward, D. P., Murray, A. T.,Phinn, S. R., 2000, "A stochastically constrained cellular model of urban growth" Computers, Environment and Urban Systems 24 539-558

WBUPLA, 1995 Wuhan Urban Planning Record (Wuhan Press, Wuhan)

White, R.,Engelen, G., 2000, "High resolution integrated modelling of the spatial dynamics of urban and regional systems" Computers, Environment and Urban systems 24 383-440 
White, R., Engelen, G.,Uljee, I., 1997, "The use of constrained automata for high-resolution modelling of urban land-use dynamics" Environmentand Planning B: Planning and Design 24 $323-343$

Wu, F., 1998, "An experiment on the generic polycentricity of urban growth in a cellular automata city" Environment and Planning B: Planning and Design 25 731-752

Wu, F., 1998, "SimLand: a prototype to simulate land conversion through the integrated GIS and CA with AHP-derived transition rules" International Journal of Geographic Information Science 12(1) $63-82$

Wu, F., 2000, "A parameterised urban cellular model combining spontaneous and self-organizing growth". GIS and Geocomputation (Innovations in GIS 7). P. Atkinson and D. Martin. (Taylor \& Francis, New York): 73-86

Wu, F., 2002, "Calibration of stochastic cellular automata: the application to rural-urban land conversions" International Journal of Geographical Information Science 16(8) 795-818

Wu, F.,Webster, C. T., 1998, "Simulation of land development through the integration of cellular automata and multi-criteria evaluation" Environment and Planning B: Planning and Design 25

Wu, F.,Yeh, A. G.-O., 1997, "Changing spatial distribution and determinants of land development in Chinese cities in the transition from a centrally planned economy to a socialist market economy: a case study of Guangzhou" Urban Studies 34(11) 1851-1879

Yeh, A. G.,Li, X., 2001, "A constrained CA model for the simulation and planning of sustainable urban forms by using GIS" Environment and Planning B: Planning and Design 28733 - 753 